\title{
Effect of Microwave Heating on the Sol-Gel Process of Silica Gels ${ }^{+}$
}

\author{
Samantha L. Flores-López ${ }^{1}$, Sara F. Villanueva ${ }^{1}$, Miguel A. Montes-Morán ${ }^{1}$, Guillermo Cruz ${ }^{2}$, \\ Julián G. Garrido ${ }^{2}$ and Ana Arenillas 1,* \\ 1 Instituto de Ciencia y Tecnología del Carbono, INCAR-CSIC, Francisco Pintado Fe, 26, 33011 Oviedo, Spain; \\ email1@gmail.com (S.L.F.-L.); email2@gmail.com (S.F.V.); email3@gmail.com (M.A.M.-M.) \\ 2 Departamento de Ciencias, Universidad Pública de Navarra, Edificio Los Acebos, Campus de Arrosadía, \\ 31006 Pamplona, Spain; email4@gmail.com (G.C.); email5@gmail.com (J.G.G.) \\ * Correspondence: ana.arenillas@csic.es \\ + Presented at the 2nd International Online-Conference on Nanomaterials, 15-30 November 2020; Available \\ online: https://iocn2020.sciforum.net/.
}

Published: 15 November 2020

\begin{abstract}
Synthesis of silica gels with tailored textural properties using the sol-gel process has been extensively studied. However, even with the inclusion of several steps and special techniques, the entire conventional procedure is still complex and time-consuming for their large scale production. The use of microwave heating could be an effective alternative. Until now, this technology has been only used for the drying step, but it could be applied to the whole process in order to reduce the synthesis time. In the present study, silica xerogels were prepared via acid-basic synthesis from different mixtures of TEOS, ethanol and $\mathrm{HCl}$ (used as silica precursor, solvent and catalyst respectively). Conventional and microwave heating were applied to the precursor solutions at different exposure configurations to evaluate the effect of this technology at each step on the sol-gel process. Porosity characterization showed a positive effect of microwaves on the silica gel structure. The analysis of these porosity results evidence for the first time interactions between microwave radiation and functionalities of the reactants, offering not only a reduction around $90 \%$ of the synthesis time, but also the possibility of using moderate operating conditions and a simple process for the synthesis of silica gels.
\end{abstract}

Keywords: Microwave heating; Silica gels; Porosity; Synthesis time

Publisher's Note: MDPI stays neutral with regard to jurisdictional claims in published maps and institutional affiliations.

(C) 2020 by the authors. Licensee MDPI, Basel, Switzerland. This article is an open access article distributed under the terms and conditions of the Creative Commons Attribution (CC BY) license (http://creativecommons.org/licenses/by/4.0/). 